\title{
Molecular Prevalence of Entamoeba Species among Diarrheal Patients in Eastern Kenya
}

\author{
Caroline Makena Lepore, Lucy Kamau, Esther Kanduma
}

\section{ABSTRACT}

\begin{abstract}
Data on the epidemiology of Entamoeba infections in Eastern part of Kenya is scanty. Diagnostic tests in use have limited capacity to differentiate common infecting species. The performance of Polymerase Chain Reaction (PCR) to differentiate between pathogenic Entamoeba histolytica and two nonpathogenic species $E$. dispar and $E$. moshkovskii is largely undetermined. Therefore, this study sought to determine the prevalence and associated factors for Entamoeba infections and evaluate the performance of PCR to differentiate Entamoeba complex species among diarrheal patient in Eastern region of Kenya. Stool samples were obtained from 400 patients attending Meru Teaching and Referral Hospital (MTRH) presenting with diarrhea. Samples were processed by direct wet mount using normal saline and iodine stain for microscopic examination. Entamoeba species differentiation was done using PCR targeting the 16S rRNA gene. A total of $33(8.3 \%)$ samples had Entamoeba cysts/trophozoites by microscopy while $29(7.3 \%)$ were identified as $E$. histolytica by PCR. Entamoeba infections was most common among adults $23(5.8 \%)$ and in females $20(5 \%)$. The sensitivity of microscopy was $29 / 29(100 \%$; $95 \%$ CI $88.1 \%-100 \%)$ with a specificity $367 / 371$ (98.9\%; 95\% CI $97.3 \%$ - 99.7\%). In multivariate analysis, factors that independently influenced Entamoeba infection included sources of drinking water, use of toilet with water, regular use of soap or sanitizer, having diarrhea that persists for two weeks and stool consistency. Entamoeba infection was found to be responsible for most diarrhea condition especially among children. Patients hygienic and sanitation characteristics contributes significantly to Entamoeba infection. The performance of microscopy to detect Entamoeba infection is comparable to those of PCR except for the lack of species differentiation. Molecular species differentiation will improve disease diagnosis, control and management. Continuous monitoring of patient presenting with diarrhea for Entamoeba infection would improve treatment outcomes.
\end{abstract}

Keywords: Diarrheal diseases, Eastern Kenyan, Entamoeba species, Entamoeba dispar, Entamoeba moshkovskii, epidemiology, molecular diagnostics.

\section{INTRODUCTION}

Worldwide about 1 million people die each year from diarrhea majorly due to unsafe drinking-water, poor sanitation and hygiene (Center for Disease Control and Prevention, 2016). Diarrhea is a life-threatening condition associated with a substantial mortality especially for children under five years (Center for Disease Control and Prevention, 2016). Sadly, in Africa, two out of five people do not have a proper source of drinking water (World Health Organization, 2014). Kenya is among the countries confronted with underprivileged sanitation and unsafe drinking water circumstances especially in the slums and rural areas. Poor sanitation predisposes individuals to diarrhea, cholera, dysentery, typhoid, and polio (World Health Organization, 2019). One of the causes of diarrhea is parasitic infections such as amoebiasis caused by Entamoeba histolytica (Development Initiative organization, 2018). Diarrhea
Published Online: January 24, 2022

ISSN: 2684-5199

DOI : 10.24018 /ejbio.2022.3.1.304

\section{M. Lepore*}

Department of Zoological Science,

Kenyatta University, Nairobi, Kenya.

(e-mail: leporecaro@gmail.com)

L. Kamau

Department of Animal Science,

Kenyatta University, Nairobi, Kenya.

(e-mail: kamaulucy05@gmail.com)

E. Kanduma

Department of Biochemistry,

University of Nairobi, Nairobi, Kenya.

(e-mail: estherkanduma@gmail.com)

*Corresponding Author

resulting from amoeba infection is common in sub-Saharan African countries, an example is Kenya (Centre for Disease Control and Prevention, 2015).

The genus Entamoeba comprises of six species colonizing human intestinal lumen include E. histolytica, E. dispar, $E$. moshkovskii, E. poleki, E. coli and E. hartmanni (Begum et al., 2015). Morphologically E. histolytica, E. dispar and E. moshkovskii are alike but differ biochemically and genetically (Zebardast et al., 2014). The E. histolytica infection is associated with significant morbidity and mortality early detection and differentiation is therefore imperative. The existence of nonpathogenic species causes confusion in the diagnosis of intestinal amoebiasis and E. histolytica is frequently inaccurately reported (López-López et al., 2017). Molecular identification of pathogenic E. histolytica and nonpathogenic Entamoeba spp (Entamoeba dispar/Entamoeba moshkovskii/Entamoeba bangladeshi) has important role in clinical management of patients with amoebiasis (Nowak, 2015). Molecular epidemiology 
therefore crucial in understanding species diversity for accurate treatment and avoidance of emergence of antimicrobial resistance among the nonpathogenic strains (Nowak, 2015). This study therefore sought to determine molecular epidemiology of Entamoeba infection and evaluated the test performance of microscopy using PCR as gold standard to detect Entamoeba infection among diarrheal patients in Meru County, Kenya.

\section{METHODS}

\section{A. Study Setting, Design and Data Collection}

\section{1) Ethical Considerations}

The research protocol was presented for scientific and ethical approvals by the Scientific Steering Committee and the Ethical Review Committee of Kenyatta University (KU/ERC/APPROVAL/VOL.1(51)). Permission to conduct this research was given by both NACOSTI (NACOSTI/P/17/33314/18190) and Meru County government. A written informed consent was obtained from all the patients.

This cross-sectional study enrolled consenting patients presenting with diarrhea attending Meru Teaching and Referral Hospital assuming 50\% of the diarrhea patients were due to Entamoeba infection. Using the formula for estimating the population proportion with specified relative precision described by Lemeshow et al., (1990) setting the $\alpha$ at 0.05 , a total of 400 patients were recruited to achieve 0.95 power. The study consecutively enrolled consenting patients who provided a stool sample. Structured interviews were used to gather socio-demographic, hygienic, sanitary, and clinical presentations. Face to face interviews using structured questionnaires were conducted to gather information regarding the social demographic, clinical presentations, hygiene, and sanitation related attributes of the patients.

\section{B. Laboratory Analysis}

\section{1) Sample Collections}

All the recruited patients were issued with a sterile prelabeled polypots and advised on how to collect at least 10 grams of stool without contaminating with urine or any foreign material. Each stool sample was then divided into two portions; approximately $5 \mathrm{~g}$ of fecal sample was used for formal ether concentration technique and the remaining stool sample frozen at $-200{ }^{\circ} \mathrm{C}$.

\section{2) Direct Microscopy}

A direct wet preparation of the fecal sample was prepared and examined under a light microscope. This was done within one hour of collection, in order to identify the trophozoites/cysts of Entamoeba species as described by Cheesbroug, (2012).

\section{3) Formal Ether Stool Concentration}

The formal ether concentration technique was used to concentrate the faecal parasite cysts of Entamoeba spp as described by Cheesbroug, (2012). Briefly, $10 \mathrm{ml}$ of $10 \%$ formal saline was put in a clean mortar and 3 grams of stool was added. The large stool particles were broken down using a pestle. The mixture was then sieved through two layers of gauze into a centrifuge tube. Three (3) $\mathrm{ml}$ of ether was added into the centrifuge tube, capped and shaken vigorously then centrifuged at $2000 \mathrm{rpm}$ for 2 minutes. The mixture separated into four layers, using an applicator stick the thick plug of debris and fatty material was loosened and the supernatant discarded leaving the sediment. The sediments were picked using Pasteur pipette and transferred to a clean slide, covered with coverslip then examined microscopically using x10 and $\mathrm{x} 40$ objectives with condenser iris closed to give good contrast. If Entamoeba cysts were seen, a few drops of lugols iodine was added to the remaining sediment in centrifuge tube and transferred to clean slide for microscopic examination. Those found to contain Entamoeba cysts were identified and preserved at -200C for DNA extraction.

\section{4) Polymerase Chain Reaction Characterization}

\section{a) DNA Extraction}

Patients' stool samples were used to extract DNA using the QIAamp DNA mini-kit (Qiagen GmbH, Hilden, Germany) according to the manufacturer's instructions. The quality of DNA was measured using UV spectrophotometer ND- 1000 (NanoDrop Technologies, Wilmington, DE, USA).

\section{b) PCR Amplification}

The Entamoeba spp was subtyped using multiplex PCR assay targeting the $16 \mathrm{~S}$ ribosomal RNA gene, modified from method described by Zerbardast et al., (2014). In the final volume of $20 \mu \mathrm{l}$, the master mix contained $1 \mu \mathrm{l}$ forward and reverse primers, $10 \mu \mathrm{l} \mathrm{Maq} \mathrm{taq} \mathrm{enzyme,} 2 \mu 1$ nuclease free water and $10 \mathrm{ng}$ of extracted DNA $(2 \mu \mathrm{l})$. The primers sequences used in this reaction were: Entamoeba forward primer 5'-ATGCACGAGAGCGAAAGCAT-3';

Entamoeba moshkovskii reverse primer 5'-

TGACCGGAGCCAGAGACAT-3'; Entamoeba dispar reverse primer 5'-CACCACTTACTATCCCT-ACC-3' and Entamoeba histolytica reverse primer 5'GATCTAGAAACAATGCTTCTCT-3'.The PCR amplifications were done in a GeneAmp PCR system 9700 (Applied biosystem) with initial denaturation at $95{ }^{\circ} \mathrm{C}$ for 10 minutes, followed by 35 cycles at $95{ }^{\circ} \mathrm{C}$ for 30 seconds denaturation, annealing at $60^{\circ} \mathrm{C}$ for 30 seconds and extension at $72{ }^{\circ} \mathrm{C}$ for 30 seconds, with a final extension at $72{ }^{\circ} \mathrm{C}$ for 5 minutes. The PCR products were visualized using a $5 \%$ cyber green stained agarose gel. The positive controls included known DNA extracts of E. histolytica-HM1: IMSS, $E$. dispar-SAW 760 and E. moshkovskii-Laredo strain while nuclease free water was used as negative control.

\section{Statistical Analysis}

Descriptive statistics: frequency (\%), mean, standard deviation, median Interquartile range was used to describe the patients' characteristics and laboratory parameter. The test performance (sensitivity, specificity, predictive values, and kappa statistics) was analyzed as follows: Sensitivity = number of true positive (TP)/sum of the number of TP and number of false negative (FN). Specificity $=$ Number of true negatives (TN)/sum of TN and the number of false positives (FP). The positive predictive value $(\mathrm{PPV})=\mathrm{TP} / \mathrm{sum} \mathrm{TP}+\mathrm{FP}$; while the negative predictive value $(\mathrm{NPV})=\mathrm{TN} / \mathrm{TN}+\mathrm{FN}$. The $95 \%$ confidence interval for the test performance were also calculated. Cohen's kappa coefficient (k) analyses was used to test the agreement of tests against a reference standard. Factors associated with Entamoeba infection was achieved using logistics regression analysis. The prevalence of Entamoeba infection was determined for all patients. In 
bivariate analyses, odds ratios (OR) and $95 \%$ confidence intervals (CI) for the association between Entamoeba infection and socio-demographic, hygienic and sanitation, clinical presentation factors were calculated using Poisson regression. In multivariate analyses, a manual backward elimination approach was used to reach the most parsimonious model including factors that were associated with Entamoeba infection among study patients at the significance level of $\mathrm{P} \leq 0.05$. All statistical analyses were performed using STATA v 13 (StataCorp LP, College Station, TX, USA).

\section{RESULTS}

\section{A. Demographic Characteristics of Study Patients}

All the 400 patients recruited in this study provided stool sample and demographic information and were included in analysis $(100 \%$ response rate). Table I summarizes the baseline characteristics of study patients. There were near equal number of females $201(50.3 \%)$ and 199 (49.7\%) male patients. The mean age of the patients was 27.9 (Standard Deviation - SD 18.6) years with median age of 24 years (interquartile range $(\mathrm{IQR})=13-39.5$ years). Among the study patients there were $43(10.8 \%)$ children under five years and $62(15.5 \% ; 95 \%$ CI $12.3 \%-19.4 \%)$ elderly patients aged 51 years and above. The majority 177 (44.3\%) of the patients had secondary level of education.

The majority 231 (57.7\%) of the patients sourced drinking water from pipped water source, $175(47.8 \%)$ stored drinking water in containers with lids, $169(42.3 \%)$ treated drinking water by boiling while $236(59 \%)$ disposed their sluice water into the environment. Further, only $75(18.7 \%)$ had access to toilet or latrines with covers while $163(40.8 \%)$ of the patients washed their hands with soap or used hand sanitizers.

The majority $375(93.8 \%)$ of patients had fever, 250 (62.5\%) had diarrhea for two weeks, while 43 (10.8\%) had diarrhea lasting longer than 14 days. Further, majority 199 (49.8\%) study patients had mild dehydration while only 6 $(1.5 \%)$ of the patients were severely malnourished and 67 $(16.88 \%)$ being categorized as malnourished. Majority of the patients $176(44 \%)$ had watery stools.

TABLE I: DESCRIPTIVE CHARACTERISTICS OF STUDY PATIENTS

\begin{tabular}{|c|c|c|c|c|c|}
\hline Variables & Units & Frequency & Percent & \multicolumn{2}{|c|}{$95 \% \mathrm{CI}$} \\
\hline \multirow{2}{*}{ Gender } & Female & 201 & 50.3 & 45.3 & 55.2 \\
\hline & Male & 199 & 49.7 & 44.8 & 54.7 \\
\hline \multirow{7}{*}{ Age (Years) } & Median (IQR) & $\begin{array}{c}24(13- \\
39.5)\end{array}$ & & & \\
\hline & 1 to 10 & 62 & 15.5 & 12.3 & 19.4 \\
\hline & 11 to 20 & 118 & 29.5 & 25.2 & 34.2 \\
\hline & 21 to 30 & 62 & 15.5 & 12.3 & 19.4 \\
\hline & 31 to 40 & 61 & 15.3 & 12 & 19.1 \\
\hline & 41 to 50 & 35 & 8.8 & 6.3 & 12 \\
\hline & $\geq 51$ & 62 & 15.5 & 12.3 & 19.4 \\
\hline \multirow{4}{*}{$\begin{array}{l}\text { Education } \\
\text { Level }\end{array}$} & Informal & 46 & 11.5 & 8.7 & 15 \\
\hline & Primary & 80 & 20 & 16.4 & 24.2 \\
\hline & Secondary & 177 & 44.3 & 39.4 & 49.2 \\
\hline & Tertiary & 97 & 24.3 & 20.3 & 28.7 \\
\hline \multirow{4}{*}{$\begin{array}{c}\text { Main Source } \\
\text { of Drinking } \\
\text { Water }\end{array}$} & $\begin{array}{c}\text { Borehole and } \\
\text { Open well }\end{array}$ & 111 & 27.9 & 23.4 & 32.4 \\
\hline & Pipped & 211 & 52.8 & 47.7 & 57.7 \\
\hline & Rivers/Springs & 57 & 14.3 & 10.9 & 18.1 \\
\hline & $\begin{array}{c}\text { Water } \\
\text { Vendors }\end{array}$ & 21 & 5 & 3.3 & 7.9 \\
\hline
\end{tabular}

\begin{tabular}{|c|c|c|c|c|c|}
\hline \multirow{3}{*}{$\begin{array}{l}\text { Water } \\
\text { Storage }\end{array}$} & $\begin{array}{c}\text { Container with } \\
\text { Lid }\end{array}$ & 175 & 43.8 & 38.9 & 48.7 \\
\hline & $\begin{array}{l}\text { Container } \\
\text { without Lid }\end{array}$ & 143 & 35.8 & 31.2 & 40.6 \\
\hline & Jerrycans & 82 & 20.5 & 16.8 & 24.8 \\
\hline \multirow{3}{*}{$\begin{array}{l}\text { Water } \\
\text { treatment }\end{array}$} & Boiling & 169 & 42.3 & 37.5 & 47.2 \\
\hline & Chemicals & 140 & 35 & 30.5 & 39.8 \\
\hline & Stand to Settle & 91 & 22.8 & 18.9 & 27.1 \\
\hline $\begin{array}{l}\text { Availability } \\
\text { of }\end{array}$ & Yes & 75 & 18.7 & 15.2 & 22.9 \\
\hline $\begin{array}{l}\text { Toilet/Latrine } \\
\text { with Cover }\end{array}$ & No & 325 & 81.3 & 77.1 & 84.8 \\
\hline \multirow{3}{*}{$\begin{array}{l}\text { Disposal of } \\
\text { Sluice Water }\end{array}$} & Environment & 236 & 59 & 54.1 & 63.7 \\
\hline & Septic Tank & 121 & 30.3 & 25.9 & 35 \\
\hline & Sewage & 43 & 10.8 & 8.1 & 14.2 \\
\hline \multirow{3}{*}{$\begin{array}{c}\text { Hand } \\
\text { Washing }\end{array}$} & $\begin{array}{l}\text { After using } \\
\text { Toilet }\end{array}$ & 117 & 29.3 & 25 & 33.9 \\
\hline & $\begin{array}{l}\text { Before Food } \\
\text { Preparation }\end{array}$ & 144 & 36 & 31.4 & 40.8 \\
\hline & Before Meals & 139 & 34.8 & 30.2 & 39.6 \\
\hline \multirow{2}{*}{$\begin{array}{l}\text { Presence of } \\
\text { Fever }\end{array}$} & Yes & 375 & 93.8 & 90.9 & 95.7 \\
\hline & No & 25 & 6.3 & 4.3 & 9.1 \\
\hline \multirow{2}{*}{$\begin{array}{c}\text { Did This } \\
\text { Diarrhea Last } \\
\text { Longer than } \\
\text { 14 Days? } \\
\end{array}$} & Yes & 43 & 10.8 & 8.1 & 14.2 \\
\hline & No & 357 & 89.2 & 85.8 & 91.9 \\
\hline \multirow{4}{*}{$\begin{array}{l}\text { Presenting } \\
\text { Symptoms }\end{array}$} & $\begin{array}{c}>3 \\
\text { Loose/Watery } \\
\text { Stools/Day }\end{array}$ & 248 & 62 & 57.1 & 66.6 \\
\hline & $\begin{array}{l}\text { Blood in } \\
\text { Stools }\end{array}$ & 8 & 2 & 1 & 4 \\
\hline & $\begin{array}{l}\text { Increased } \\
\text { Thirst }\end{array}$ & 90 & 22.5 & 18.7 & 26.9 \\
\hline & $\begin{array}{l}\text { Sunken eyes } \\
\text { (Dehydration) } \\
\end{array}$ & 54 & 13.5 & 10.5 & 17.2 \\
\hline \multirow{4}{*}{ Dehydration } & Mild & 199 & 49.8 & 44.8 & 54.7 \\
\hline & Moderate & 106 & 26.5 & 22.4 & 31.1 \\
\hline & Normal & 54 & 13.5 & 10.5 & 17.2 \\
\hline & Severe & 41 & 10.3 & 7.6 & 13.6 \\
\hline \multirow{4}{*}{$\begin{array}{l}\text { Nutritional } \\
\text { Status }\end{array}$} & Malnutrition & 67 & 16.8 & 13.4 & 20.8 \\
\hline & $\begin{array}{c}\text { Mild } \\
\text { Malnutrition }\end{array}$ & 210 & 52.5 & 47.6 & 57.4 \\
\hline & Nourished & 117 & 29.3 & 25 & 33.9 \\
\hline & $\begin{array}{c}\text { Severe } \\
\text { Malnutrition }\end{array}$ & 6 & 1.5 & 0.7 & 3.3 \\
\hline \multirow{4}{*}{$\begin{array}{c}\text { Stool } \\
\text { Consistency }\end{array}$} & Bloody & 25 & 1.3 & 0.5 & 3 \\
\hline & Mucoid & 173 & 43.3 & 38.5 & 48.2 \\
\hline & Watery & 176 & 44 & 39.2 & 48.9 \\
\hline & $\begin{array}{c}\text { Watery and } \\
\text { Bloody }\end{array}$ & 46 & 11.5 & 8.7 & 15 \\
\hline
\end{tabular}

CI-Confidence Interval

\section{B. Prevalence of Entamoeba Infections among Study Patients}

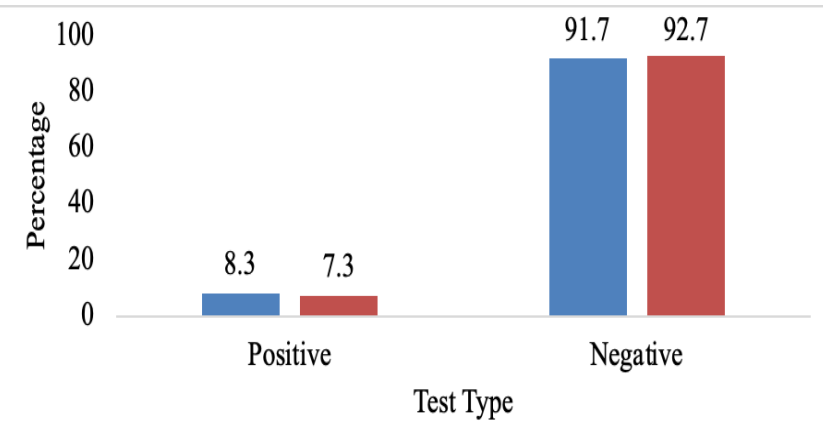

- Microscopy $\square \mathrm{PCR}$

Fig. 1. Prevalence of Entamoeba infection among study patients using microscopy and PCR. 
Prevalence of Entamoeba infection varied depending on the test used: Using microscopy 33/400 (8.3\%; 95\% CI 5.6\% - 10.9\%) had Entamoeba infection while 29/400 (7.3\%; 95\% CI $4.9 \%-10.3 \%$ ) were positive by PCR (Fig. 1).

\section{Sensitivity and Specificity of Microscopy using PCR as Gold Standard}

Table II summarizes the test performance of microscopy using PCR as gold standard. The microscopy results were concordant with those of PCR 396/400 (99\%; 95\% CI 97.5\% -99.7\%). A kappa value of 0.9641 which measures the level of agreement between tests showed almost perfect agreement between microscopy and PCR to detect Entamoeba infection. The sensitivity of microscopy was $29 / 29(100 \%$; $95 \%$ CI $88.1 \%-100 \%)$ with a specificity of $367 / 371(98.9 \%$; $95 \% \mathrm{CI}$ $97.3 \%$ - 99.7\%). The positive predictive value (PPV) of microscopy was $29 / 33(87.9 \%$; 95\% CI $71.8 \%$ - 96.6\%) with a negative predictive value (NPV) of $367 / 367$ (100\%; 95\% CI $99 \%$ - 100\%) (Table II).

TABLE II: PERFORMANCE OF MICROSCOPY AGAINST PCR RESULTS AS THE GOLD STANDARD TO DETECT ENTAMOEBA INFECTION

\begin{tabular}{|c|c|c|c|c|c|c|c|c|}
\hline \multirow[b]{2}{*}{ Test } & \multicolumn{8}{|c|}{ PCR (Gold Standard) } \\
\hline & $\mathrm{N}$ & $\begin{array}{c}\text { Concordant } \\
\text { Results (\%) } 95 \% \\
\text { CI }\end{array}$ & $\begin{array}{c}\text { Sensitivity (\%) } \\
95 \% \mathrm{CI}\end{array}$ & $\begin{array}{c}\text { Specificity (\%) } \\
95 \% \mathrm{CI}\end{array}$ & $\begin{array}{l}\text { NPV (\%) } \\
95 \% \mathrm{CI}\end{array}$ & $\begin{array}{c}\text { PPV (\%) 95\% } \\
\text { CI }\end{array}$ & Карра & Agreement \\
\hline Microscopy & 400 & $99(97.5-99.7)$ & $100(88.1-100)$ & $98.9(97.3-99.7)$ & $100(99-100)$ & $87.9(71.8-96.6)$ & 0.9641 & Almost perfect \\
\hline
\end{tabular}

N-Number; \%-Percentage; CI-Confidence Interval; NPV; Negative Predictive Value; PPV; Positive Predictive Value

\section{Linear Regression Model}

In the final linear regression model (Table III), factors significantly associated with Entamoeba infection in the multivariate analysis were; patients who obtained drinking water from water boreholes/open wells (adjusted odd ration $\mathrm{aOR}=2.8,95 \% \mathrm{CI}=1.2-6.6 ; \mathrm{p}=0.022)$, from rivers and springs $(\mathrm{aOR}=3.3,95 \% \mathrm{CI}=1.2-8.9 ; \mathrm{p}<0.018)$, from water vendors $(\mathrm{aOR}=5.1,95 \% \mathrm{CI}=1.5-17.7 ; \mathrm{p}=0.009)$, patients who used toilets without cover $(\mathrm{aOR}=294.8,95 \%$ $\mathrm{CI}=16.6-539 ; \mathrm{p}=0.0001)$, patients whose diarrhea lasted longer than 14 days $(\mathrm{aOR}=11.9,95 \% \mathrm{CI}=4.1-33.7 ; \mathrm{p}<$ $0.0001)$ and patients who had bloody stool $(\mathrm{aOR}=6.4,95 \%$ $\mathrm{CI}=1.2-32.9 ; \mathrm{p}=0.026)$ and watery and bloody diarrhea $(\mathrm{aOR}=5.7,95 \% \mathrm{CI}=1.5-21.8 ; \mathrm{p}=0.01)$ were independently associated with high rates of Entamoeba infection. On the other hand, patients who disposed their sluice water into sewage systems $(\mathrm{aOR}=0.2,95 \% \mathrm{CI}=0.03$ $-0.9 ; \mathrm{p}=0.036)$, those who cleaned their hands using soap and water or sanitizers $(\mathrm{aOR}=0.08,95 \% \mathrm{CI}=0.024-0.0 ; \mathrm{p}$ $=0.0001)$ were independently associated with reduced rates of Entamoeba infection.

TABLE III: UNIVARIATE AND MULTIVARIATE REGRESSION ANALYSIS OF FACTORS ASSOCIATED WITH ENTAMOEBA INFECTION AMONG STUDY PATIENTS

\begin{tabular}{|c|c|c|c|c|c|c|c|}
\hline \multirow[t]{2}{*}{ Variables } & \multicolumn{3}{|c|}{ Infected } & \multicolumn{2}{|c|}{ Bivariate } & \multicolumn{2}{|c|}{ Multivariate } \\
\hline & $\mathrm{N}$ & Freq & $\%$ & $\mathrm{uOR}(95 \% \mathrm{CI})$ & P Value & $\mathrm{aOR}(95 \% \mathrm{CI})$ & $\mathrm{p}$ Value \\
\hline \multicolumn{8}{|c|}{ Gender } \\
\hline Male & 201 & 20 & 9.9 & $0.7(0.3-1.3)$ & 0.238 & $0.6(0.3-1.3)$ & 0.246 \\
\hline Female & 199 & 13 & 6.5 & Referent & Referent & Referent & Referent \\
\hline \multicolumn{8}{|c|}{ Age (Years) } \\
\hline 1 to 10 & 62 & 4 & 6.5 & $0.6(0.2-1.9)$ & 0.372 & $0.6(0.2-1.9)$ & 0.384 \\
\hline 11 to 20 & 118 & 7 & 5.9 & $0.5(0.2-1.5)$ & 0.229 & $5.3(0.4-67.8)$ & 0.202 \\
\hline 21 to 30 & 62 & 4 & 6.5 & $0.6(0.2-1.9)$ & 0.372 & $0.7(0.2-2.3)$ & 0.529 \\
\hline 31 to 40 & 61 & 10 & 16.4 & $1.5(0.6-3.8)$ & 0.449 & $1.5(0.6-3.9)$ & 0.409 \\
\hline 41 to 50 & 35 & 1 & 2.9 & $0.3(0.03-2.1)$ & 0.199 & $0.3(0.03-2.1)$ & 0.199 \\
\hline$\geq 51$ & 62 & 7 & 11.3 & Referent & Referent & Referent & Referent \\
\hline \multicolumn{8}{|c|}{ Main Source of Drinking Water } \\
\hline Borehole and Open well & 111 & 12 & 10.8 & $2.5(1.1-6)$ & 0.035 & $2.8(1.2-6.6)$ & 0.022 \\
\hline Rivers/Springs & 57 & 8 & 14.1 & $3.2(1.3-8.5)$ & 0.014 & $3.3(1.2-8.9)$ & 0.018 \\
\hline Water Vendors & 21 & 4 & 19 & $4.4(1.4-14.5)$ & 0.013 & $5.1(1.5-17.7)$ & 0.009 \\
\hline Pipped & 211 & 9 & 4.3 & Referent & Referent & Referent & Referent \\
\hline \multicolumn{8}{|c|}{ Water Storage } \\
\hline Jerrycans & 82 & 10 & 12.2 & $0.9(0.01-0.7)$ & 0.023 & $0.1(0.02-0.9)$ & 0.047 \\
\hline Container without Lid & 143 & 10 & 6.7 & $0.6(0.3-1.3)$ & 0.203 & $1.3(0.6-2.8)$ & 0.468 \\
\hline Container with Lid & 175 & 13 & 74.0 & Referent & Referent & Referent & Referent \\
\hline \multicolumn{8}{|c|}{ Use Toilet with Cover } \\
\hline Yes & 75 & 10 & 13.3 & Referent & Referent & Referent & Referent \\
\hline No & 325 & 23 & 7.1 & $39.2(4.4-351)$ & 0.0001 & $\begin{array}{c}294.8(16.6- \\
539) \\
\end{array}$ & 0.0001 \\
\hline \multicolumn{8}{|c|}{ Disposal of Sluice Water } \\
\hline Sewage & 43 & 3 & 6.9 & $0.9(0.3-3.1)$ & 0.886 & $0.2(0.03-0.9)$ & 0.036 \\
\hline Septic Tank & 121 & 12 & 9.9 & $1.3(0.6-2.7)$ & 0.481 & $0.6(0.2-1.7)$ & 0.31 \\
\hline Environment & 236 & 18 & 7.6 & Referent & Referent & Referent & Referent \\
\hline \multicolumn{8}{|c|}{ Hand washing } \\
\hline After Using Toilet & 117 & 9 & 7.7 & $0.8(0.4-1.9)$ & 0.886 & $0.2(0.3-0.9)$ & 0.036 \\
\hline Before Food Preparation & 144 & 11 & 7.7 & $0.8(0.4-1.8)$ & 0.481 & $0.6(0.2-1.7)$ & 0.31 \\
\hline Before Meals & 139 & 13 & 9.4 & Referent & Referent & Referent & Referent \\
\hline \multicolumn{8}{|c|}{ Use Soap or Hand Sanitizers } \\
\hline Yes & 163 & 4 & 1.8 & $0.2(0.01-0.6)$ & 0.004 & $\begin{array}{c}0.08(0.024- \\
0.3)\end{array}$ & 0.0001 \\
\hline
\end{tabular}




\begin{tabular}{|c|c|c|c|c|c|c|c|}
\hline No & 237 & 29 & 12.2 & Referent & Referent & Referent & Referent \\
\hline \multicolumn{8}{|c|}{ Fever } \\
\hline Yes & 375 & 32 & 8.5 & $1.9(0.3-14.3)$ & 0.51 & $1.1(0.1-9.4)$ & 0.956 \\
\hline No & 25 & 2 & 8 & Referent & Referent & Referent & Referent \\
\hline \multicolumn{8}{|c|}{ "Had Diarrhea in the Past 2 Weeks } \\
\hline Yes & 43 & 27 & 62.8 & $23.2(9.6-56.2)$ & 0.0001 & $11.9(4.1-33.7)$ & 0.0001 \\
\hline No & 357 & 6 & 1.7 & Referent & Referent & Referent & Referent \\
\hline \multicolumn{8}{|c|}{ Presenting Symptoms } \\
\hline >3 Loose/Watery Stools/Day & 248 & 27 & 10.9 & $3.3(1.0-10.8)$ & 0.05 & $0.9(0.2-4.6)$ & 0.869 \\
\hline Blood in Stools & 8 & 0 & 0 & ND & 0.995 & ND & 0.995 \\
\hline Increased Thirst & 90 & 3 & 3.3 & $1.7(0.3-8.2)$ & 0.531 & $1.6(0.1-17.5)$ & 0.717 \\
\hline Sunken eyes (Dehydration) & 54 & 3 & 5.6 & Referent & Referent & Referent & Referent \\
\hline \multicolumn{8}{|c|}{ Nutritional Status } \\
\hline Malnutrition & 67 & 9 & 13.4 & $3.1(1.1-9.3)$ & 0.04 & & 0.989 \\
\hline Mild Malnutrition & 210 & 19 & 9.1 & $2.1(0.8-5.7)$ & 0.647 & & 0.989 \\
\hline Severe Malnutrition & 6 & 0 & 0.0 & ND & 0.993 & ND & 0.990 \\
\hline Nourished & 117 & 5 & 4 & Referent & Referent & Referent & Referent \\
\hline \multicolumn{8}{|c|}{ Stool Consistency } \\
\hline Bloody & 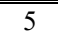 & 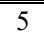 & 100 & $58.3(13.9-244.1)$ & 0.0001 & $6.4(1.2-32.9)$ & 0.026 \\
\hline Watery and Bloody & 46 & 15 & 32.6 & $17.9(5.2-61.7)$ & 0.0001 & $2.5(0.7-9.3)$ & 0.174 \\
\hline Watery & 176 & 10 & 5.7 & $3.4(0.9-12.4)$ & 0.062 & $5.7(1.5-21.8)$ & 0.01 \\
\hline Mucoid & 173 & 3 & 1.7 & Referent & Referent & Referent & Referent \\
\hline
\end{tabular}

$\mathrm{N}=$ total population; Freq- Pfrequency; \%- Percentage; OR- Odds Ratio; CI-Confidence Interval; uOR and aOR-Un and Adjusted Odd Ratio respectively; P-Level of Significance; $\mathrm{P} \leq 0.05$ indicates the relationship is significant

\section{Discussion}

Amoebiasis caused by intestinal parasite Entamoeba histolytica, has an estimated worldwide prevalence of 500 million infected people and is responsible for 40,000 100,000 deaths each year (Mulinge et al., 2021). It is an important health problem, especially in developing countries (Sebastian et al., 2007). Microscopy, the main diagnostic test used in many hospitals is unable to distinguish between $E$. histolytica and Entamoeba dispar (Nowak, 2015; LópezLópez et al., 2017). More sensitive and specific molecular techniques that are able to distinguish $E$. histolytica from $E$. dispar and E. moshkovskii have been developed (Nowak, 2015). Inevitably, prompt management of amoebiasis requires accurate diagnosis to distinguish between species of public health importance. It is on this background that this study was designed to determine the prevalence and associated factors of Entamoeba infections in diarrheal patients attending MTRH.

The prevalence of Entamoeba infection in this population was dependent on the test used: Using microscopy $8.3 \%$ of the study patients were found infected with Entamoeba while 29/400 (7.3\%) patients were found infected with E. histolytica by PCR. No other Entamoeba strains were identified by PCR. Varied prevalence of Entamoeba has been reported globally. Infection with E. histolytica, the protozoan parasite that causes amoebic colitis and liver abscess, results in 34 million to 50 million symptomatic cases of amoebiasis (all illnesses caused by E. histolytica, including amoebic dysentery) worldwide each year, causing 40 thousand to 100 thousand deaths annually (Stauffer et al., 2006). In Africa, the burden of amoebiasis is high with an estimated E. histolytica infection median rate of 796 per 100,000 people (WHO, 2019). Studies conducted in Kenya indicated prevalence of $6-11 \%$ of $E$. histolytica / E. dispar in children at selected hospitals and $11-32 \%$ among adults (Sebastian et al., 2007; Kagira et al., 2011; Mbae et al., 2013). Moreover, the prevalence of E. histolytica by quantitative PCR was recorded at $15 \%$ in Bungoma County, Western Kenya (Easton et al.,
2016), while a much lower prevalence of $0.4 \%$ was reported among children with vertically transmitted HIV infection (Matey et al., 2016). This data suggests that amoebiasis is a heavy burden among the Kenyan population which is also plagued by other diseases such as malaria, HIV-AIDS, tuberculosis and other non-communicable diseases. In other regions, amoebiasis is also a problem in the developed world in travelers, immigrants, and men who have sex with men (Haque et al., 2003). Entamoeba histolytica usually causes asymptomatic infection but in a minority of cases causes symptoms ranging from a few loose stools to profuse bloody diarrhea (Kosek et al., 2003). The difference in this prevalence can be explained largely due to epidemiological, environmental distribution difference, poor personal hygiene practices, environmental sanitation and ignorance of healthpromotion practices.

Environmental, socio-economic, demographic and hygiene-related behavior is known to influence the transmission and distribution of intestinal parasitic infections (Norhayati et al., 2003). In this study hygienic and sanitary status such as obtaining household waters from unhygienic water sources including water vendors and lack of access to covered toilets or pit latrines were independently associated with higher risk of Entamoeba infections. This agrees with previous studies which have shown that the rate of infection by E. histolytica differs among countries, socio-economic and sanitary conditions and populations (Al-Harthi et al., 2007). The infection is highly endemic throughout poor and socioeconomically deprived communities in the tropics and subtropics. A study in Brazil identified place of residence, age, ingestion of raw vegetables and drinking water quality as important risk factors (Norhayati et al., 2003).

Proper waste disposal such as the use of sewage system rather than environment and practicing recommended hygienic guidelines such as hand with soap or sanitizers were protective against Entamoeba infection. Reports show that E. histolytica in humans is transmitted directly following fecaloral transmission routes. The risk pattern identified in our study follows this logic. In particular, the transmission routes via contaminated hands play a major role, documented in our study with a more than three- fold risk increase if hands are 
not washed properly, in agreement with a study by Duc et al., (2011).

This study also found association of Entamoeba infection with stool consistency. Patients who had bloody or watery stool remained independently associated with higher Entamoeba infection. Even though presence of bloody stool remains a significant sign of intestinal parasite, indeed, studies have established the fecal oral route for the transmission of Entamoeba (Anuar et al., 2012). Watery stool or bloody stool have higher chance of spreading fecal droplets across wider surface compared to firm stool which could be a cause of infection and re-infection especially to those in contact with these patients. The presence of watery stool or bloody stool poses greater risk of further transmission within the family. A study by Al-Areeqi et al, (2017) showed that within the family, the presence of other infected family members significantly increased the odds of an individual being infected with E. histolytica. A previous study from Malaysia found a similar finding with E. dispar (Anuar et al., 2012). The infection could easily be passed on through contaminated food and drinks prepared by infected family members who have inadequate personal hygiene. The trophozoite of Entamoeba spp. survives for a short time but the cyst lives longer and withstands unfavorable conditions; it can be found on the hands and clothes of children as well as in containers used for washing clothes and in shower trays, which implies that contact with an infected person's belongings and water they have used also transmits the infection (Roberts et al., 2009).

Although age was not found to influence Entamoeba infection in this study, previous reports have shown an increasing prevalence of Entamoeba infection to reach its highest rate among patients aged $21-30$ years then decreasing to its lowest among those aged more than 40 years (Al-Areeqi et al., 2017). By contrast, a previous study among Malaysian rural communities reported a significantly higher prevalence of $E$. dispar infection among patients younger than 15 years (Anuar et al., 2012). Gender in this study was not found to be associated with Entamoeba infection. However, gender has been cited as a key factor for Entamoeba infection with more infections occurring among males. This difference could be explained by a higher exposure of adult males to sources of infections as a result of their daily activities such as more frequent consumption of contaminated outdoor food, contaminated water sources and contact with infected individuals (Al-Areeqi et al, 2017).

Accurate laboratory diagnosis of any disease-causing pathogen is critical for proper management as false results can potentially have severe consequences such as serving as reservoirs for onward transmission and death (Elston, 2006). Additionally, presenting false results can significantly undermine both clinical confidence and credibility of laboratory results, consequently resulting in wrong prescription that may cause drug wastage (Footedar et al., 2007) and unnecessary costs. In the current study based on PCR test results as the gold standard, the sensitivity and specificity of microscopy was $100 \%$ and $98.9 \%$ respectively. The PPV and NPV of microscopy was $87.9 \%$ and $100 \%$ respectively. Lower sensitivity $64.2 \%$ and specificity $83.6 \%$ of microscopy were recorded in a previous study in western Kenya (Emisiko et al., 2020). On the other hand, sensitivity of microscopy in the diagnosis of E. histolytica seems to be varied with some studies reporting values ranging between $10 \%$ and $60 \%$ (Fotedar et al., 2007; Pereira et al., 2014). Diagnostic tests occasionally show varied sensitivities and specificities depending on the setting especially in endemic and non-endemic sites (Abu-Madi et al., 2017).

Entamoeba infections are traditionally diagnosed via microscopic examination of stool samples, fresh or fixed. Microscopic examination of stool specimens in saline wet mount is a less sensitive technique even when viewed by an expert microscopist (Parija et al., 2014). Moreover, this technique is often subjective and is prone to misdiagnosis and has other limitations. For instance, in microscopy one cannot distinguish between cysts and trophozoites within degenerated polymorphonuclear cells (Shirley et al., 2018). The Center for Disease Control recommends examination of adequate samples within 30 minutes of collection to improve sensitivity of microscopy. It is important to note that changes in sample $\mathrm{pH}$ as well as prior use of antibiotics before sample collection kills trophozoites decreasing sensitivity of microscopy (Shirley et al., 2018). Due to the limitations of microscopy, other techniques have been developed including serological based techniques like Rapid Diagnostic Tests (RDTs) and molecular based techniques such as polymerase chain reaction (PCR) (Aly et al., 2018). PCR has been adopted as the gold standard method for the diagnoses of amoebiasis (Shirley et al., 2018). However, utilization of PCR in routine diagnosis of E. histolytica in resource limited settings is impractical (Emisiko et al., 2020). As such, a combination of serologic tests with microscopy detection offers the best approach to diagnosis of E. histolytica [30]. However, in most resource limited settings, microscopy is the only diagnostic test used for detection of most enteric parasites (Emisiko et al., 2020). It is important that continuous monitoring and evaluation of the test is done to ensure reliability of microscopy. Moreover, laboratory personnel have different levels of training, experience, and skills.

One key objective of this study was to identify $E$. histolytica, E. dispar and E. moshkovskii using PCR assay. By microscopy all the Entamoeba isolates were identified as E. histolytica. However, using specie specific PCR, 29 $(87.9 \%)$ out of 33 isolates identified by microscopy were found to be E. histolytica while the remaining 4 did not amplify and thus could not be typed by PCR. This is not unique to the current study only, Lau et al., (2013) found nine samples identified by microscopy as negative for real-time PCR even upon retesting. It is possible that the samples which were detected positive by microscopy but not by PCR may belong to other Entamoeba species such as E. coli, E. polecki and E. hartmanni (Parija et al., 2014). A study done by Petri and co-workers in Bangladesh showed the limitations of microscopy, whereby only $40 \%$ of children diagnosed by microscopy were proven to have E. histolytica infection by PCR test (Petri et al., 2000).

Studies have repeatedly shown that pathogenic amoeba, E. histolytica is indistinguishable in its cyst and trophozite stages from E. dispar and E. moshkovskii, the non-pathogenic species (Khhairnar and Parija, 2007). It has also been shown that the sensitivity and specificity of microscopy is less optimal in differentiating the various species of Entamoeba 
(Tanyuksel et al., 2003). Given the discrepancies of microscopy, various approaches have been implemented. The epidemiology of Entamoeba can be further be studied by culturing trophozoites and determining isoenzyme patterns by gel electrophoresis (Lau et al., 2013). These techniques are costly, time-consuming, laborious and not practical for regular diagnosis (Lau et al., 2013). An enzyme immunoassay kit (TechLab II antigen test) has been specifically designed for the detection of E. histolytica. However, this kit is marketed for examination of stool samples only though fixed stools samples have been found not suitable for enzyme-linked immunosorbent assay (ELISA) (Qvarnstrom et al., 2005). Due to the need to study the epidemiology of Entamoeba, the polymerase chain reaction (PCR) is now the method of choice, and this technique has been approved by the World Health Organization (WHO) (Hamzah et al., 2010). In a study conducted by Stark et al. (2008), it was demonstrated that PCR has improved sensitivity and specificity over ELISAbased kits. PCR also has the ability of specifically targeting and detecting E. histolytica, E. dispar, and E. moshkovskii infections (Parija et al., 2014).

\section{CONCLUSION}

The following conclusions can therefore be drawn from the findings of this study; that prevalence of Entamoeba infection still remains a significant problem among patients presenting with diarrhea diseases. The importance of hygiene and sanitary status as important avenue for Entamoeba infection cannot be overstated as observed in this study in agreement with many others. In the absence of molecular assays, microscopy is a reliable test in detecting Entamoeba though its limitation in differentiating different Entamoeba species is still a challenge.

\section{ACKNOWLEDGMENT}

This work was part of Master of Science degree for CML in Applied Parasitology of Kenyatta University. CML, LK and EK conceived the study. CML collected and analyzed the data and prepared the draft manuscript. LK and EK provided guidance and mentorship during the implementation of the study. All authors reviewed and approved the final manuscript.

\section{FUNDING}

This study was funded from students' loan.

\section{CONFLICT OF INTEREST}

Authors declare that they do not have any conflict of interest.

\section{REFERENCES}

Abu-Madi, M., Boughattas, S., Behnke, J. M., Sharma, A., Ismail, A. (2017). Coproscopy and molecular screening for detection of intestinal protozoa. Parasit Vectors, 10.
Al-Harthi, S., Jamjoom, M. (2007). Diagnosis and Differentiation of Entamoeba infection in Makhah Al Mukarramah using microscopy and stool Antigen Detection Kits. W J Med Sci, 2: 15-20.

Al-Areeqi, M. A., Sady, H., Al-Mekhlafi, H., Anuar, T., Al-Adhroey, A., Atroosh, W., et al (2017). First molecular epidemiology of Entamoeba histolytica, E. dispar and E. moshkovskii infections in Yemen: different species-specific associated risk factors. Tropical Medicine and International Health. 22: 493-504.

Aly, N. S., Bayoumi, I., Selem, R., Kardoush, M., Rashed, G., Moharam, A. (2018). A Novel Nano Magnetic Beads Dot ELISA Immunoassay and Its Application on the Detection of Giardia lamblia Coproanti-gen. Iran J Parasitol, 13(4): 532-40.

Anuar, T. S., Al-Mekhlafi, H. M., Ghani, M. K. A., Bakar, E. A., Azreen, S. N., Salleh, F. M., et al. (2012). Molecular epidemiology of amoebiasis in Malaysia: highlighting the different risk factors of Entamoeba histolytica and Entamoeba dispar infections among Orang Asli communities. International Journal of Parasitology, 42: 1165 - 1175.

Begum, S., Quach, J., \& Chadee, K. (2015). Immune evasion mechanisms of Entamoeba histolytica: progression to disease. Frontiers in microbiology, 6, 1394.

Benetton, M. L., Goncalves, A. V., Meneghini, M. E., Silva, E. F., Carneiro, M. (2005). Risk factors for infection by the Entamoeba histolytica/E. dispar complex: an epidemiological study conducted in outpatient clinics in the city of Manaus, Amazon Region, Brazil. Trans R Soc Trop Med Hyg, 99: 532-540.

Center for Disease Control and Prevention. (2016). Global Water, Sanitation \& Hygiene (WASH).

Centre for Disease Control and Prevention (2015). Parasites - Amebiasis Entamoeba Histolytica Infection.

Cheesbrough, M. (2012). District Laboratory Practice in Tropical Countries. Cambridge University Press.

Development Initiative organization (2018). Enhancing access to safe water and improved sanitation services in Kenya (Issue December).

Duc, P. P., Nguyen-Viet, H., Hattendorf, J., Zinnstag, J., Cam, P., Odermatt, P. (2011). Risk factors for Entamoeba histolytica infection in an agricultural community in Hanam province, Vietnam. Parasites Vectors, 4: 102.

Easton, A. V., Oliveira, R. G., O’Connell, E. M., Kepha, S., Mwandawiro, C. S., Njenga, S. M., et al. (2016). Multi-parallel qPCR provides increased sensitivity and diagnostic breadth for gastrointestinal parasites of humans: field-based inferences on the impact of mass deworming. Parasites Vectors, 9: 38

Elston, D. M. (2006). Laboratory Results That Should Be Ignored. Med Gen Med, 8(4): 9.

Emisiko, J., Shavia, N., Shiluli, C., Kiboi, N., Wamalwa, R., Jumba, B., et al. (2020). Comparison of Microscopy and PCR for Detection of Giardia Lamblia and Entamoeba Histolytica in Human Stool Specimens in a Resource Limited Setting in Western Kenya. Ethiop J Health Sci. 30(6).

Fotedar, R., Stark, D., Beebe, N., Marriott, D., Ellis, J., Harkness, J. (2007). PCR Detection of Entamoeba histolytica, Entamoeba dispar, and Entamoeba moshkovskii in Stool Samples from Sydney, Australia. J Clin Microbiol, 45(3): 1035-7.

Hamzah, Z., Petmitr, S., Mungthin, M., Leelayoova, S., Chavalitshewinkoon- Petmitr, P. (2010). Development of multiplex real-time polymerase chain reaction for detection of Entamoeba histolytica, Entamoeba dispar and Entamoeba moshkovskii in clinical specimens. Am J Trop Med Hyg, 83: 909-913.

Haque, R., D. Mondal, B. D. Kirkpatrick, Akther, S., Farr, B. M., Sack, R. B., Petri, Jr., W. A. (2003). Epidemiologic and clinical characteristics of acute diarrhea with emphasis on E. histolytica infections in preschool children in urban slum of Dhaka, Bangladesh. Am. J. Trop. Med. Hyg, 69: 398-405.

Kagira, J. M., Maina, N., Njenga, J., Karanja, S. M., Karori, S. M., Ngotho, J. M. (2011). Prevalence and types of coinfections in sleeping sickness patients in Kenya (2000/2009). J Trop Med.

Khairnar, K., Parija, S. C. (2007). A novel nested multiplex polymerase chain reaction (PCR) assay for differential detection of Entamoeba histolytica, E. moshkovskii and E. dispar DNA in stool samples. BMC Microbiol, 7: 47.

Kosek, M., Bern, C., Guerrant, R. L. (2003). The global burden of diarrhoeal disease, as estimated from studies published between 1992 and 2000. Bull, 81: 197-20.

Lau, Y. L., Anthony, C., Fakhrurrazi, S. A., Ibrahim, J., Ithoi, I., Mahmud, R. (2013). Real-time PCR assay in differentiating Entamoeba histolytica, Entamoeba dispar, and Entamoeba moshkovskii infections in Orang Asli settlements in Malaysia. Parasites Vectors, 6: 250. 
Lemeshow, S., Hosmer, D.K., Klar, J., Lwanga, S.K., World Heath Organization. (1990). World health Organization. Adequacy of samples size in health studies. Chichester: Wiley.

López-López, P., Martínez-López, M. C., Boldo-León, X. M., HernándezDíaz, Y., Gonzalez- Castro, T. B., Tovilla-Zarate, C., et al., (2017). Detection and differentiation of Entamoeba histolytica and Entamoeba dispar in clinical samples through PCR-denaturing gradient gel electrophoresis. Brazilian Journal of Medical and Biological Research, $50(4), 1-7$.

Matey, E. J., Tokoro, M., Nagamoto, T., Mizuno, T., Saina, M. C., Xiuqiong, B., et al. (2016). Lower prevalence of Entamoeba species in children with vertically transmitted HIV infection in Western Kenya. AIDS, 30: 803-5.

Mbae, C. K., Nokes, D. J., Mulinge, E., Nyambura, J., Waruru, A., Kariuki, S. (2013). Intestinal parasitic infections in children presenting with diarrhoea in outpatient and inpatient settings in an informal settlement of Nairobi, Kenya. BMC Infect Dis, 13: 243.

Mulinge, E., Mbae, C., Ngugi, B., Irungu, T., Matey, E., \& Kariuki, S. (2021). Entamoeba species infection in patients seeking treatment for diarrhea and abdominal discomfort in Mukuru informal settlement in Nairobi, Kenya. Food and Waterborne Parasitology, 23, e00122.

Norhayati, M., Fatmah, M. S., Yusof, S., Edariah, A. B. (2003). Intestinal parasitic infections in man: a review. Med J Malaysia, 58: 296-305.

Nowak, P. (2015). Entamoeba histolytica - Pathogenic Protozoan of the Large Intestine in Humans. Journal of Clinical Microbiology and Biochemical Technology, 1, 010-017.

Parija, S. C., Mandal, J., Ponnambath, D. K. (2014). Laboratory methods of identification of Entamoeba histolytica and its differentiation from look-alike Entamoeba spp. Tropical Parasitology, 4(2): 90.

Pereira, V. V., Conceição, A. S., Maximiano, L. H. S., Belligoli, L. Q. G., Silva, E. S., Pereira, V. V. (2014). Laboratory diagnosis of amebiasis in a sample of students from southeastern Brazil and a comparison of microscopy with enzyme-linked immunosorbent assay for screening of infections with Entamoeba sp. Revista da Sociedade Brasileira de Medicina Tropical. 47(1):52

Petri, W. A., Haque, R., Lyerly, D., Vines, R. (2000). Estimating the impact of amoebiasis on health. Parasitol Today, 16: 320-321.

Qvarnstrom, Y., James, C., Xayavong, M., Holloway, B. P., Visvesvara, G. S., Sriram, R., et al. (2005). Comparison of real-time PCR protocols for differential laboratory diagnosis of Amebiasis. J Clin Microbiol, 43: 5491-5497.

Roberts, L., Janovy Jr. J. (2009). Foundation of Parasitology McGraw-Hill: New York.

Sebastian, H. J. V., Stark, D. J., Fotedar, R., Marriott, D., John, T. E. J. T., Harkness, J.L (2007). Amoebiasis: current status in Australia. M J A, 186: 412-416.

Shirley, D.-A. T., Farr, L., Watanabe, K., Moonah, S. (2018). A Review of the Global Burden, New Diagnostics, and Current Therapeutics for Amebiasis. Open Forum Infect Dis, 5(7): ofy161.

Stauffer, W., Abdalla, M., Ravdin, J. (2006). Prevalence and Incidence of Entamoeba histolytica Infection in South Africa and Egypt. Archives of Medical Research. 37: 265-268.

Tanyuksel, M., Petri, W. A. (2003). Laboratory diagnosis of Amebiasis. Clin Microbiol Rev, 16: 713-729.

World Health Organization. (2014). Progress on Drinking Water and Sanitation.

World Health Organization. (2019). Water sanitation hygiene.

Zebardast, N., Haghighi, A., Yeganeh, F., Tabaei, S. J. S., Gharavi, M. J., Fallahi S., et al., (2014). Application of Multiplex PCR for Detection and Differentiation of Entamoeba histolytica, Entamoeba dispar and Entamoeba moshkovskii. Iranian J Parasitol, 466-473. 